\title{
Applying Desirability Functions to preference modelling in low-energy building design optimization
}

\author{
Robinson, E. ${ }^{1}$, Hopfe, C.J. ${ }^{1}$, Emmerich, M. ${ }^{2}$, Yevseyeva, I. ${ }^{3}$, Wright, J.A. ${ }^{1}$ \\ ${ }^{1}$ Loughborough University, Loughborough, UK \\ ${ }^{2}$ Leiden University, Leiden, The Netherlands \\ ${ }^{3}$ De Montfort University, Leicester, UK
}

\begin{abstract}
Building performance optimization is a valuable aid to design decision-making. Most existing research takes an 'a posteriori' approach, where stakeholder preferences are considered after deriving optimised results. Whilst this approach yields technically optimal solutions, it overlooks sub-optimal solutions that still satisfy stakeholder preferences. This research develops a technique to incorporate preferences into optimization by applying a "desirability function" to each criterion for multiple stakeholders. The approach enables the tradeoffs between decision-makers to be visualised as a Pareto frontier and aids "democratic" decision-making. Hence, incorporating preferences in advance of optimization may increase the likelihood of finding a desirable solution.
\end{abstract}

\section{Introduction}

Building design is inherently complex, with multiple stakeholders involved; many decisions need to be made and there is a diverse range of potential solutions. In this situation, decision-makers experience "information overload" and adopt filtering techniques to reduce the problem to a manageable scale (Malhotra, 1982; Payne, 1976). Building Performance Simulation (BPS) and computational optimization can be used to select a subset of candidate solutions with significantly reduced energy demand (Evins, 2013). Most existing studies consider 'a posteriori' decision-making, where stakeholder preferences are expressed after optimization, by selecting preferred solutions from the Pareto frontier (Evins, 2013; Nguyen et al, 2014). However, if the optimization process is conducted before considering decision-makers' preferences, then some acceptable solutions may be ruled out because they are sub-optimal. Incorporating preferences into the optimization process may lead to the selection of different potential solutions.

The role of BPS was succinctly summarised by the keynote speaker at the BSO 2018 conference: to provide better decision-making and to allow for "democratic" decision-making between stakeholders (Clarke, 2018).

Harrington (1965) introduced the idea of a 'desirability function' as a method of incorporating preferences into decision-making. Research by Emmerich et al (2016), builds on that concept by applying a profile of acceptance probability to each decision-maker for each criterion and deriving an expected consensus score. The method shows great potential for democratic decision-making between stakeholders. The concept of desirability has, to the authors' knowledge, not been applied to building performance and simulation. The novelty of this research is the application of desirability functions to both input parameters and the resulting performance criteria, in advance of any knowledge of the results. Optimization conventionally uses the Pareto frontier to illustrate tradeoffs between performance measures; similarly, the decision-making process between two stakeholders could be considered as a negotiation process, with trade-offs between what is acceptable to each participant.

This technique is applied to early stage design because decisions made at this stage are often based on client preferences, without recourse to building performance simulation (BPS) (Negendahl, 2015). The selection of window-to-wall ratio is an early stage design decision, which has a significant impact on a building's performance, which is particularly important when striving to achieve the stringent standards of the Passivhaus low-energy building standard (Hopfe and McLeod, 2015). Hence, considering the impact of decisions made in early stage design is crucial to gaining confidence that low-energy aspirations are realistic.

The outcome of this research is to aid decision-making by giving feedback to stakeholders in a form that highlights the trade-offs between achieving a technically optimal solution and satisfying stakeholder preferences.

\section{Methods}

This research aims to explore the impact of decisionmakers' preferences in low-energy building design. Stakeholders will make 'a priori' choices on annual specific heat demand, over-heating frequency and the window-to-wall ratio of each façade. The design decision variables of wall material, shading and window-to-wall ratio (WWR) are varied, as described in Table 2. For simplicity, and proof of concept, the paper will limit the number of decision makers to two, the low energy (Passivhaus) consultant and the project client. These stakeholders were chosen because they typify the conflict between performance targets and aesthetic preference, which is central to many design decisions in low-energy building. The focus here is on the methodology; a simplified example is selected deliberately to allow for concentration on the method. 


\section{Case Study}

The proposed community building in the Findhorn EcoCommunity, Scotland was used to illustrate the concept. The design brief included a requirement to evaluate the potential to comply with the Passivhaus standard, subject to site constraints and construction costs, whilst making the most of attractive views, via large areas of glazing. Passivhaus is an international low-energy building standard with stringent targets. It can be achieved by limiting the annual heating demand to a maximum of $15 \mathrm{kWh} / \mathrm{m}^{2}$ per annum and limiting over-heating frequency to less than $10 \%$ of occupied hours (Passivhaus Trust, 2013). The U-values for the building surfaces are as per the design specification and were defined with a low-energy building in mind, as described in Table 1.

Table 1: $U$-values for low-energy building.

\begin{tabular}{|l|l|}
\hline Building Surface & U-value $\left(\mathbf{W} / \mathbf{m}^{\mathbf{2}} \mathbf{K}\right)$ \\
\hline External Walls & 0.15 \\
\hline Roof & 0.10 \\
\hline Ground Floor & 0.85 \\
\hline Windows & 0.78 \\
\hline
\end{tabular}

When considering the same case study building, Hopfe et al (2017) cite glazing ratio as the most influential global parameter, with significant impacts on both space heating demand and over-heating frequency. Clearly, decisions on the sizing and position of windows are made in the early stages of design and are difficult to modify once regulatory approval is granted. The same could be said for wall materials. In contrast, shading devices may be retrofitted, if over-heating becomes a problem when the finished building is in use. A simplified case study was considered here. However, the findings can be applied to aid decision-making between different building forms and to incorporate a wider range of criteria.

\section{Selection of Performance Measures}

The optimization process had two objectives:

1. To maximise the probability of acceptance of a prospective solution by the Passivhaus consultant;

2. To maximise the probability of acceptance by the client.

For each stakeholder, the probability of acceptance is determined by the desirability function for the following criteria:

- Annual specific heat demand $\left(\mathrm{kWh} / \mathrm{m}^{2}\right.$ per annum)

- Over-heating frequency (\% of occupied hours)

- Window-to-Wall Ratio (\%)

The desirability profiles (shown in Table 3 ) were used to derive a numerical score for the overall probability acceptance for each. Assumptions were made on the decision-makers' preferences for annual specific heat demand, over-heating frequency and WWR, based on the literature; the Passivhaus consultant's preference is chosen to reflect best practice in Passivhaus design for a cold climate (Goia, 2016). The client's preference is based on previous research for the same case study building (Hopfe et al, 2017).

\section{Design Decision Variables}

The design decision variables are described in Table 2. Window-to-Wall Ratio (WWR) was chosen because decisions on this criterion are made in the early stage of design and it has a strong influence on energy use and over-heating; furthermore, decision-makers may have aesthetic preferences on WWR (Scanferla and Motuziene, 2017). Thermal mass (in the form of wall material) was considered because of its impact on moderating overheating in low-energy building (Ridley et al, 2014). Shading was selected because of its role in preventing over-heating (Goia, 2016). Also, it impacts the appearance of a building design; if blinds are chosen, then they block the view when in use, conflicting with a key aspect of the design brief: that the design should maximise views of the landscape. The numeric criteria of annual specific heating demand and over-heating hours were studied because they are a requirement of a Passivhaus certification pathway (Passivhaus Trust, 2013).

Table 2: Design Variables.

\begin{tabular}{|c|c|c|}
\hline $\begin{array}{l}\text { Design } \\
\text { Decision } \\
\text { Variable } \\
\end{array}$ & $\begin{array}{l}\text { Variable } \\
\text { Type }\end{array}$ & Options \\
\hline $\begin{array}{c}\text { Wall } \\
\text { material }\end{array}$ & $\begin{array}{l}\text { Attribute of } \\
\text { candidate } \\
\text { design }\end{array}$ & $\begin{array}{l}\text { (1) Structured Insulated } \\
\text { Panels (SIPS): expanded } \\
\text { polystyrene insulation } \\
\text { between panels of } \\
\text { oriented-strand board } \\
\text { (2) Heavy Weight (HW): } \\
\text { cast concrete with external } \\
\text { expanded polystyrene } \\
\text { insulation }\end{array}$ \\
\hline Shading & $\begin{array}{l}\text { Attribute of } \\
\text { candidate } \\
\text { design }\end{array}$ & $\begin{array}{l}\text { (1) Exterior blinds absent } \\
\text { or present; } \\
\text { (2) Activated when solar } \\
\text { radiation }>120 \mathrm{~W} / \mathrm{m}^{2}\end{array}$ \\
\hline $\begin{array}{l}\text { Window-to- } \\
\text { Wall Ratio }\end{array}$ & $\begin{array}{l}\text { Optimization } \\
\text { parameter }\end{array}$ & $\begin{array}{l}10-80 \% \text {, discretised with } \\
\text { a step size of } 1 \%\end{array}$ \\
\hline
\end{tabular}

For clarity, WWR is both an input parameter and a criterion for stakeholder preferences.

\section{Desirability Optimization Process}

The aim of this process is to test whether including stakeholder preferences in the optimization process results in the selection of a different solution, when compared to preference-free optimization. Multiobjective optimization was used to explore the trade-offs between the probability of acceptance by two key stakeholders and how these relate to the performance targets and design decision variables.

The following steps are taken:

a) Defining desirability functions for each decisionmaker and criterion, as described in Table 3;

b) The objective function for the optimization is to maximize the probability of acceptance of a prospective solution for each of two decision-makers;

c) The expected consensus is calculated to illustrate whether that provides a useful measure (see the section on 'Acceptance Probability and Expected 
Table 3: Desirability Functions.

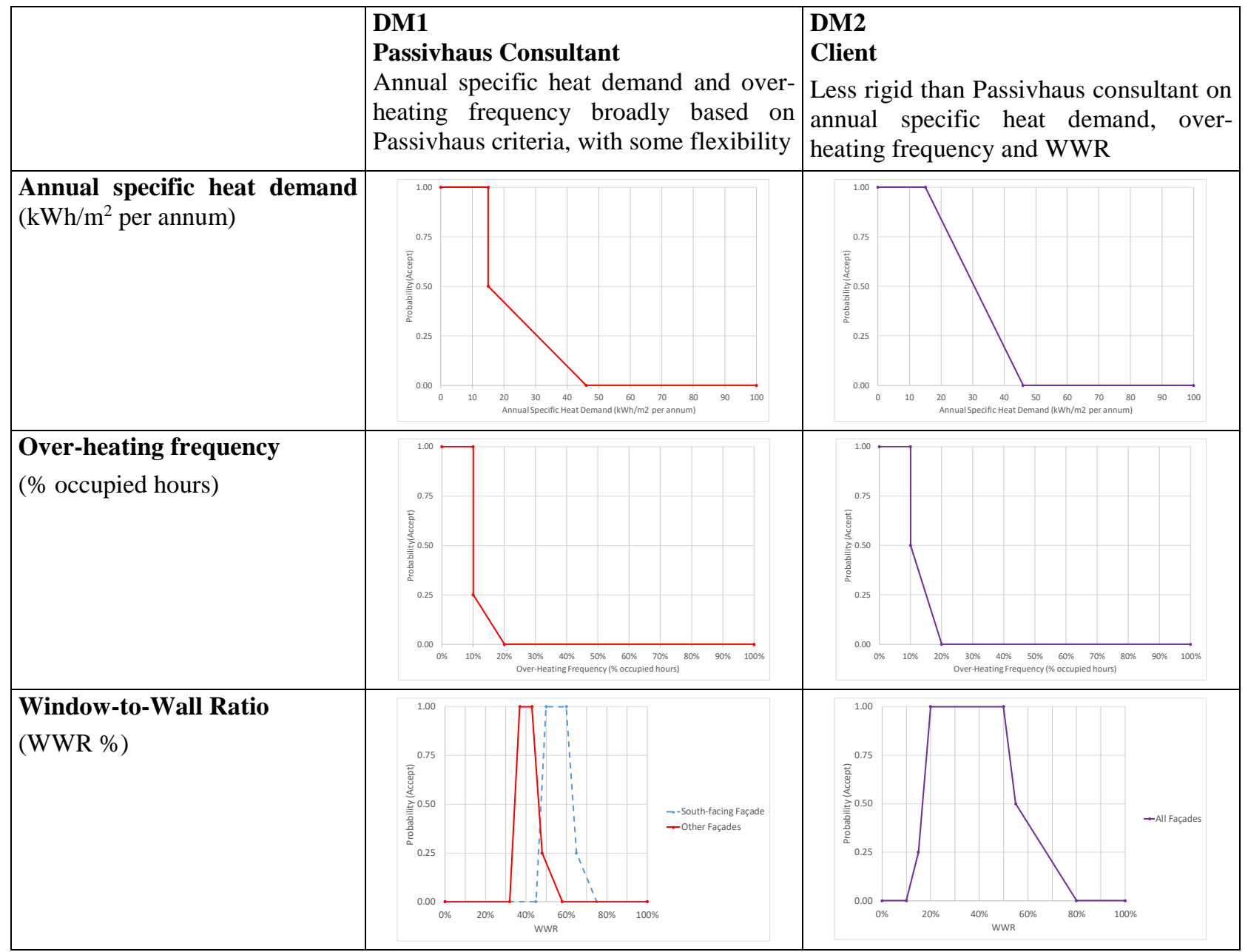

Consensus', below, for further details);

d) A single computational optimization run, including the desirability functions, is conducted across the entire range of design variables described in Table 2;

e) A comparative optimization is conducted, without incorporating the desirability functions, which seeks to minimize the conventional Passivhaus targets of:

- Annual specific heat demand;

- Occupied over-heating hours.

The results of these two optimization approaches are compared.

\section{Acceptance Probability and Expected Consensus}

The probability that a given alternative is acceptable to a decision-maker is calculated as a product of the acceptance probability of each criterion and summed to derive an expected consensus score for each prospective solution. In any multi-stakeholder, multi-criteria problem, decision-makers will need to show flexibility in some of their preferences, if consensus is to be achieved. This research will use an estimate of fuzzy preferences for each decision-maker's desire for a range of annual specific heat demand, over-heating frequency and suitable window-towall ratio (WWR) values. Desirability functions are used to derive the probability of a given attribute value being acceptable to a given decision-maker. Piecewise linear desirability functions are used. As with Derringer Suich type of desirability functions, the value of zero means not acceptable, whereas the value of 1 means that a solution fully satisfies the demand of the decision maker with respect to the criterion. By using piecewise linear functions, we add flexibility to the approach by Derringer Suich, which allows only for a very limited range of function shapes. Based on the derivation by Emmerich et al (2016), the probability that a given decision-maker $\left(\mathrm{DM}_{\mathrm{j}}\right)$ will find a given alternative $\left(\mathrm{x}_{\mathrm{i}}\right)$ acceptable overall, across criteria $\left(\mathrm{f}_{\mathrm{k}}\right)$, is calculated by:

$$
P\left(\text { DM } M_{j} \text { Accepts } x_{i}\right)=\prod_{k=1}^{3} P\left(\text { Accept } f_{k}\right)
$$

and the expected consensus score, meaning the expected number of decision makers who will agree on an option, for a given alternative $\mathrm{x}_{\mathrm{i}}$ is then derived by:

$$
E\left(x_{i}\right)=\sum_{j=1}^{2} P_{j}(\text { Acceptance })
$$

\section{Simulation and Optimization Process}

A simple two-storey geometric form of the building was considered, as shown in Figure 1. The design reflects the client's preference to make the most of attractive views and is divided into two zones, to fulfil the requirement of functional areas for retail space and a café. The WWR for the individual façades were varied, with a step size of $1 \%$. A single window was constructed to extend to the full width of the building and was centred around the midpoint of each façade. The population size for the 
optimization is twenty and the search is randomly seeded with values of:

- Wall construction material: Structured Insulated Panels (SIPS), expanded polystyrene insulation between panels of oriented-strand board (OSB), or Heavy Weight (HW), cast concrete with external expanded polystyrene insulation.

- Shading: exterior blinds absent or present, activated when solar radiation exceeds $120 \mathrm{~W} / \mathrm{m}^{2}$ during occupied hours.

- WWR between $10 \%$ and $80 \%$; chosen because, at the lower end of the range, some glazing is always needed for visual comfort and, at the top of the range, some space is needed to accommodate frames.

The EnergyPlus software package was used for the dynamic simulation of the building performance because:

a) It is commonly used in research and has a proven reputation in energy performance simulation;

b) It permits text file inputs, so it lends itself to automation and can be readily called from within existing programming languages;

c) It allows the user to modify parameters (Ascione et al, 2015; Jankovic, 2012; Nguyen et al, 2014).

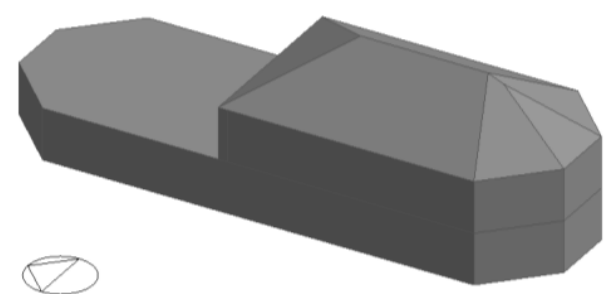

Figure 1: Case Study Building Form.

The proven technique of a genetic algorithm was used for the optimization process; the S-Metric Selection Evolutionary Multi-objective Optimization Algorithm (SMS-EMOA) (Beume et al 2007) was the chosen, as a robust and accurate state-of-the-art technique.

The objective of the optimization process is to maximise the probability of acceptance for both decision-makers.

Four preference-based optimization runs were conducted, as outlined in Table 4:

Table 4: Optimization Summary.

\begin{tabular}{|c|c|c|}
\hline Run & Variables & Restrictions \\
\hline (a) & $\begin{array}{c}\text { Wall material, } \\
\text { Shading, WWR }\end{array}$ & Desirability function \\
\hline (b) & Wall material, WWR & $\begin{array}{c}\text { Desirability function; } \\
\text { Shading absent }\end{array}$ \\
\hline (c) & Shading, WWR & $\begin{array}{c}\text { Desirability function; } \\
\text { Wall material SIPS }\end{array}$ \\
\hline (d) & $\begin{array}{c}\text { Wall material, } \\
\text { Shading, WWR }\end{array}$ & $\begin{array}{c}\text { Desirability function: } \\
\text { Shifted Profile for WWR }\end{array}$ \\
\hline
\end{tabular}

A subsequent performance-based optimization (e), which sought to minimize annual specific heat demand and overheating frequency by varying wall material, shading and WWR without applying desirability, was conducted to illustrate how results differ when preferences are not considered. In each case, a copy of the base case input data file was created and the window-to-wall ratio on each façade of the building, wall material and shading were automatically edited and EnergyPlus was called to simulate the building performance and evaluate the objectives. A total of 4000 evaluations were executed for each optimization.

The following output variables were captured:

a) Annual heating demand: sourced from the EnergyPlus output file 'eplustbl.csv'; taken from the 'District Heating [kWh]' column and divided by the 'Net Conditioned Building Area'.

b) Over-heating hours: calculated as the occupied hours when the operative temperature exceeds $25^{\circ} \mathrm{C}$.

c) Probability of acceptance for each criterion for each decision-maker and the expected consensus score (derived as described in the section 'Acceptance Probability and Expected Consensus').

\section{Results}

\section{(a) No restriction on shading or wall material}

The initial optimization run applied the desirability functions outlined in Table 3 to derive the probability of acceptance for each decision-maker, by varying shading, wall material and WWR. The entire solution set results in an acceptance score of ' 1 ' for both decision-makers, meaning that all solutions satisfy all criteria, so the expected consensus is ' 2 '. Hence, the optimization resulted in a single point, with no trade-offs between the decision-makers, so neither stakeholder needs to compromise. However, there are two performance results that achieve the optimum consensus, i.e. there are two distinct data points for annual specific heat demand and over-heating frequency closely clustered together, as illustrated in Figure 2. This can be attributed to the narrow acceptable range for DM1 (Passivhaus consultant). These two solutions do not conform to a conventional Pareto frontier for the numeric performance criteria. Hence, one solution dominates the other; this aspect may aid the selection of a single solution. Mapping these data points back to the input criteria shows that these results can be achieved for a range of combinations of WWR across the different façades. All prospective solutions have a WWR of $50 \%$ on the south façade, because this is the only value which is yields a probability of acceptance of 1 for both stakeholders.

The entire solution had shading present and a wall material of heavy-weight, which prompts an exploration of how the method performs when further restrictions are included.

\section{(b) Additional restriction: No Shading}

The application of exterior blinds may be undesirable, given that the design brief specified visibility of attractive views; hence, considering how the method behaves if shading devices are ruled-out might prove instructive.

A further optimization was conducted to analyse the impact; again, all prospective solutions yield a satisfaction score of ' 1 ' for both stakeholders. The results illustrated in Figure 2 show that over-heating frequency is greater when a 'No Shading' restriction is applied. Hence, it is possible to achieve performance within the 


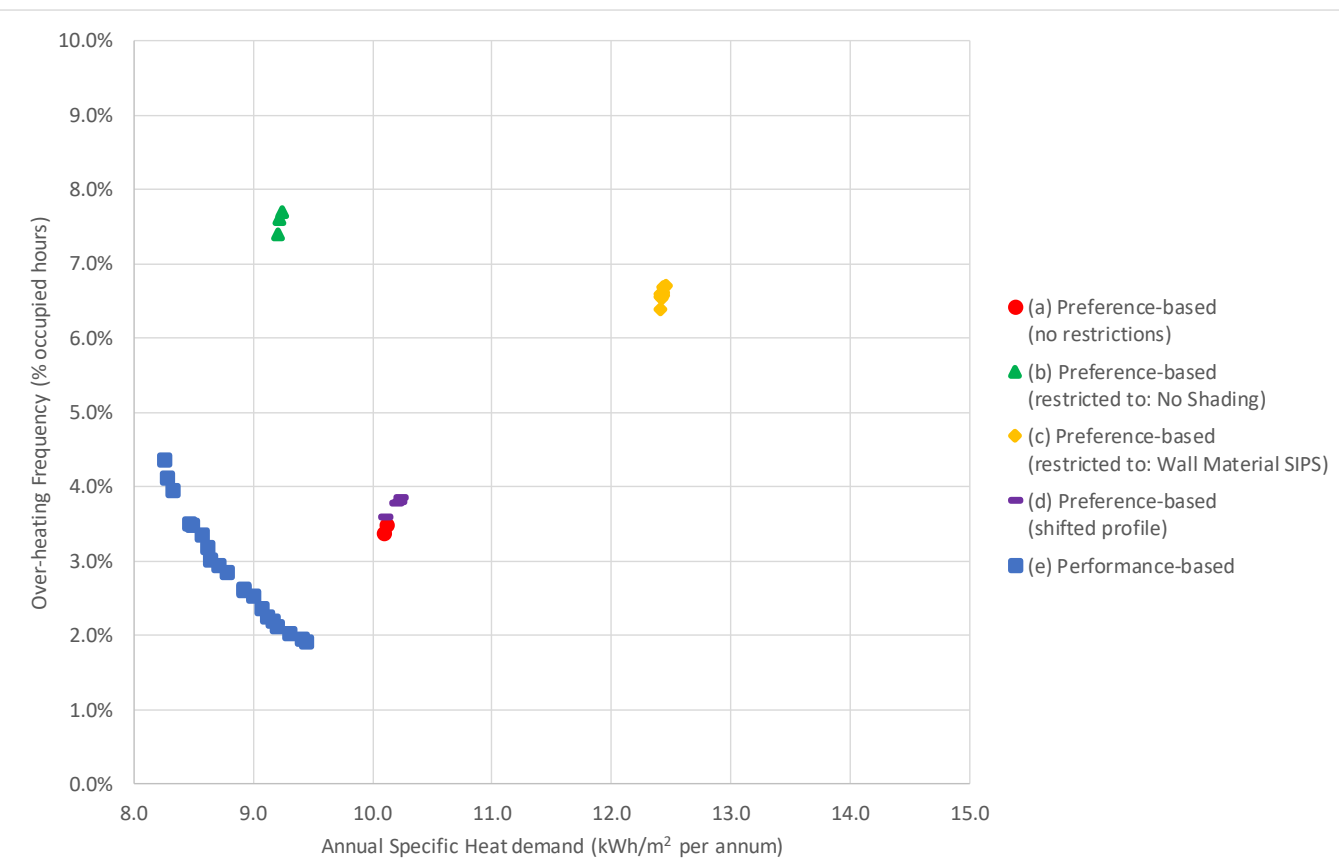

Figure 2: Comparison of preference-based optimization against conventional performance-based optimization, showing trade-offs between annual specific heat demand and over-heating frequency; the maximum values on the axes indicate Passivhaus standard limits

(a) - (c) All solutions satisfy the restrictions placed on the criteria, and have optimal solutions from each decision-maker's perspective with a probability of acceptance of 1 ;

(d) Selected solutions with probability of acceptance of 0.5 or more for both stakeholders;

(e) Conventional performance-based optimization finds greatest number of optimized solutions, in terms of the objective of minimising annual specific heat demand and over-heating frequency.

stakeholder preferences, without the presence of shading, albeit with increased incidence of over-heating. As with the previous solution set, the results can be achieved by several combinations of the input criteria of WWR on each façade.

All the data points in the 'No Shading' solution set require a wall material of 'Heavy Weight'.

\section{(c) Additional restriction: Wall Material SIPS}

The client might wish to restrict the wall material to SIPS, given that there are advantages to be gained in terms of improved air-tightness, quicker construction time and reduced cost (Kermani and Harstans, 2006) or out of a preference for low embodied-energy materials.

If the wall material is restricted to SIPS, then the optimization results again yield a set of prospective solutions, all of which give a satisfaction score of ' 1 ' for both decision-makers. The results are illustrated in Figure 2 and show that the annual specific heat demand is greater when the wall material is restricted to SIPS.

The entire solution set required shading.

\section{(d) Shifting Desirability Profile}

If the desirable range of WWR for the Passivhaus consultant is shifted by plus $5 \%$, then there is a greater overlap with the client, so one might expect there to be a wider range of potential solutions. However, the results show that there are no options that completely satisfy the preferences of both stakeholders simultaneously.

The trade-offs between decision-makers can be illustrated on a Pareto frontier, as shown in Figure 3. The dashed diagonal line shows where a solution would lie if it gave equal priority to each stakeholder. The dotted rectangle marking the top right quadrant outlines the area where the probability of acceptance for both stakeholders is 0.5 or more. The size of the dots indicates the expected consensus score. The results show that the views of DM2 (Client) have priority over the views of DM1 (Passivhaus consultant) on most occasions. Hence, it appears more challenging to satisfy the preferences of DM1. It seems intuitive that a more restrictive range of WWR makes achieving a stakeholder's preferences more challenging. One method of choosing the most suitable solution is to calculate the expected consensus and selecting the option with greatest score (Emmerich et al, 2016). In this example, the maximum expected consensus is achieved by solution [C], where DM1 (Passivhaus consultant) has

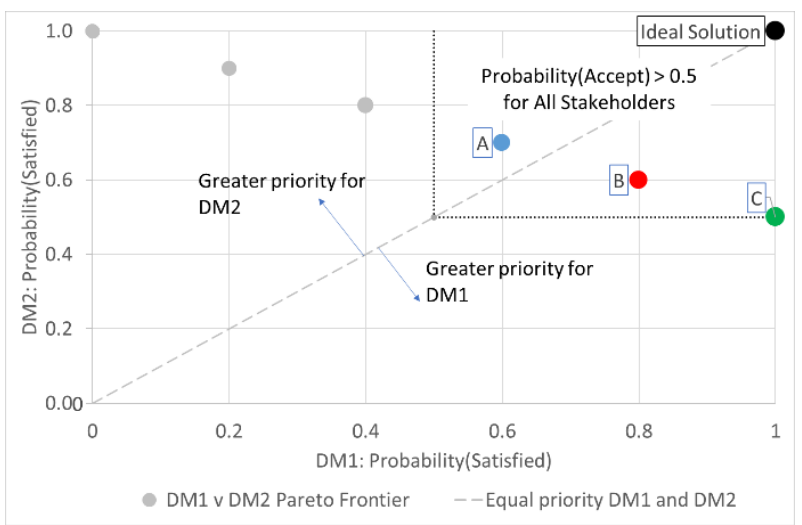

Figure 3: Trade-offs between decision-makers. 


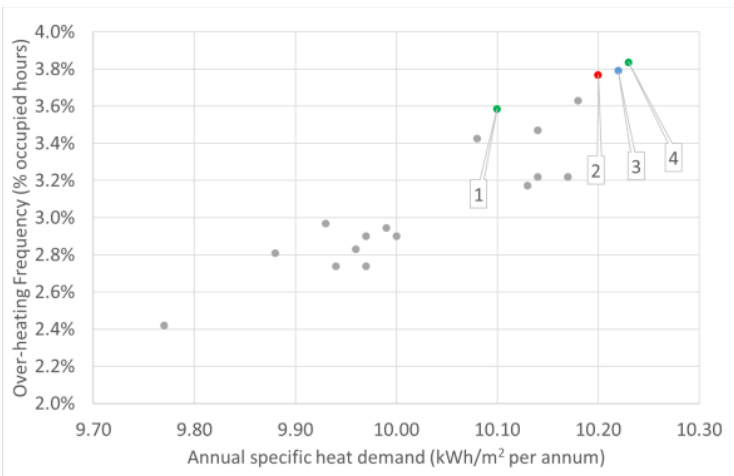

Figure 4: Preferred solutions: Shifted Profile.

a probability of acceptance of 1 and DM2 (Client) has a probability of acceptance of 0.5 ; i.e. one decision-maker makes no concessions, while the other accepts all the compromises. Hence, higher expected consensus scores are achieved for those solutions that better satisfy the preferences of DM1 (Passivhaus consultant).

An alternative method might be to select the prospective solution with the minimum distance from the ideal of both decision-makers achieving a score of ' 1 '. In this example, solution [B] where DM1 and DM2 have probabilities of acceptance of 0.8 and 0.6 , respectively, has the minimum distance to the ideal solution, as shown in Figure 3.

Three of the points on the Pareto frontier in Figure 3 ([A], [B] and [C]) equate to solutions where all stakeholders have probability of acceptance of 0.5 or more. Figure 4 illustrates how those prospective solutions map to four subtly difference performance results: $[\mathrm{A}]$ in Figure 3 corresponds to solution [3], [B] corresponds to solution [2] and [C] to solutions [1] and [4]; i.e. solutions [1] and [4] both achieve the maximum expected consensus score of 1.5 , with a probability of acceptance of 1 for DM1 (Passivhaus consultant) and 0.5 for DM2 (Client).

Figure 5, shows how solutions [1] to [4] map back to the input parameters of the WWR for each façade. Solution [1] from Figure 4 has the best performance in annual specific heat demand and over-heating frequency; Figure 5 illustrates that solution [1] (the green dotted line) has lower levels of glazing on the north and east façades, but higher levels on the south and west, compared to solutions [2], [3] and [4].

Drilling down into the details of how the different desirability functions determine the preference scores of each stakeholder reveals that the entire solution set satisfies the requirements for annual specific heat demand and over-heating frequency for both decision-makers.

Therefore, in this instance, preference scores for WWR are driving the optimization process. Hence, consensus can only be increased by decision-makers exhibiting flexibility in their preferences for WWR.

It should be noted that the entire solution selects a 'Heavy Weight' wall material and shading present.

\section{(e) Comparison to Conventional Optimization}

A conventional performance-based optimization, free of any preferences was conducted for comparison. As shown

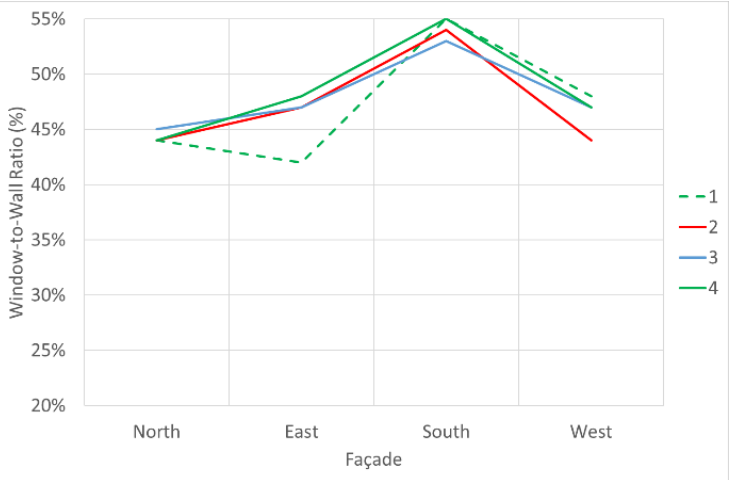

Figure 5: Input Parameters: Shifted Profile.

in Figure 2, the performance on both annual specific heat demand and over-heating frequency exceeds that for preference-based optimization. None of the performancebased optimal solutions satisfy the WWR requirements of either decision-maker. Whereas the preference-based optimization solutions do not lie on the Pareto frontier of performance optimal solutions; however, they are within the Passivhaus criteria while satisfying stakeholder preferences. Compared to performance for restricted WWR, there is potential for $16 \%$ reduction in annual specific heat demand, with the same over-heating frequency, if the stakeholders are prepared to forego their restrictions on WWR, which translates to reduced operational energy costs and reduced $\mathrm{CO}_{2}$ emissions. Conversely, the preference-based optimization (a) performs well within the Passivhaus standard. This might be viewed as an opportunity to reduce insulation U-values to achieve a reduced cost. However, the entire solution set (a) resulted in the choice of a wall material of heavyweight; so, if a subsequent decision is made to select a wall material of SIPS, then that performance may be pushed beyond the limits of the Passivhaus standard.

\section{Discussion}

The outcome of the decision-making process differs depending upon whether the stakeholder preferences are considered before or after optimization; the choice of approach determines the selected design alternative.

Four scenarios were considered:

(a) No restriction on shading or wall material;

(b) Restricted to: No shading;

(c) Restricted to: Wall material SIPS;

(d) Shifted desirability profile.

Optimization runs (a) to (c) all achieved an acceptance score of ' 1 ' for both decision-makers. All prospective solutions were sub-optimal, compared to conventional performance-based optimization. However, these solutions are more likely to adopted because they satisfy stakeholder preferences.

Optimization run (d) illustrated the trade-offs between the probability of acceptance for two decision-makers on a Pareto frontier. Selecting an individual solution can then be done by the expected consensus method. However, in this instance all of the concession is borne by DM1 (Client), so it does not appear to be in the spirit of 
compromise. Furthermore, when considering the key role of the client in the decision-making process, such a course of action seems unrealistic. It is suggested that the consensus model should be extended by a fairness measure. Shifting the profile changes the outcome, which illustrates the importance of the choice of desirability function. Also, selecting a different function for the profile may change the solution set and hence the tradeoffs between stakeholders. Future research needs to focus on ensuring realistic profiles are accurately-defined. In the example studied here, the preference for WWR determines which solutions are selected from the perspective of either decision-maker; however, other examples may see each stakeholder compromise on a different criterion.

The decision-making problem does not end with the selection of a trade-off solution between the stakeholders; a single point may map to multiple performance solutions. For example, point [C] on Figure 3 corresponds to performance solutions [1] and [4] on Figure 4. Each performance solution may be achieved by multiple combinations of input parameters.

Combining acceptance probabilities as a product assumes decisions on each criterion are independent of one another, which may not be the case. For instance, the Passivhaus consultant may favour their WWR preferences because of the impact it will have on annual specific heat demand and over-heating frequency.

On a practical level, combining probability of acceptance for a single stakeholder as a product, means that all criteria must be satisfied for an alternative to be acceptable. In complex problems it may be infeasible to concurrently satisfy the multiple preferences of even a single stakeholder, so it is important that stakeholders understand the consequences of choosing a desirability function that reaches zero.

If there is too little similarity between the desirability profiles of different stakeholders, or the participants lack flexibility, then it will be challenging to achieve an agreeable solution and it is feasible that no solutions will even partially fulfil the requirements of all stakeholders. Conversely, if there is too much similarity between the desirability profile for different stakeholders, then it is feasible for many solutions to achieve the same score for the probability of acceptance; hence, the optimization process may struggle to differentiate between competing solutions and viable choices may be lost from the results set. Applying Harrington desirability functions may resolve this issue, as the probability of acceptance changes gradually and never reaches either ' 0 ' or ' 1 '.

Furthermore, not all stakeholders have an opinion on every criterion; for instance, the architect may have no opinion on the setpoint temperature in the finished building, however it will have an impact on the energy performance. In this case the probability of acceptance is ' 1 ', which expresses indifference.

Choices made in the early stage of design may narrow the available options within the performance criteria at a subsequent stage, so it is advisable to conduct an uncertainty analysis prior to making a decision that might have a knock-on effect later in the design process. Hence, the sequencing of design decisions must be considered when incorporating desirability into the optimization process. Equally, introducing desirability into the optimization may risk jeopardising performance.

For wider application this method needs to be scalable. Adding criteria to the problem adds to the complexity of calculating the probability of acceptance; whereas, adding stakeholders increases the number of optimization objectives. An initial exploration of how the problem can be scaled-up to include more design parameters has been illustrated. Increasing the number of decision-makers may make it more challenging to achieve consensus and to illustrate the trade-offs between stakeholders. Furthermore, as the number of objectives increases, the processing time may increase exponentially, depending upon the optimization algorithm (Beume et al, 2007).

Potential refinements to the method include adding an importance weighting for each criterion for each stakeholder. Applying Harrington's desirability function for each criterion for a decision-maker may be more appropriate for the complex decision-making problem of building design. There is potential for metrics other than expected consensus to be explored, such as the distance from the ideal solution. Future work will address these issues.

\section{Conclusion}

A novel methodology was developed to include desirability into the optimization process and allow for democratic decision-making. To the authors' knowledge, this is the first paper to apply desirability functions to building performance simulation and to focus on decision-makers' preferences in the objective function. The technique has been illustrated using two decisionmakers and including both input (WWR) and output (annual specific heat demand, over-heating frequency) parameters. The profiles used were similar for each decision-maker; future work will include the contrasting viewpoint of an additional decision-maker.

The approach has the potential to achieve 'better' results by fulfilling stakeholders' preferences. However, because the product of probability of acceptance for each criterion is taken, a potential solution that was perfect in all other aspects would be rejected if it failed on a single criterion. Furthermore, taking a product of the probabilities requires that the decision for each criterion is statistically independent, i.e. the decision-maker's preference on one criterion does not have a bearing on their preference for another. This aspect needs careful consideration; for instance, the Passivhaus consultant may choose their preferences for WWR according to what they know to be effective to improve building performance or they may be motivated by the lower build cost that can be achieved by reducing the area of high-specification Passivhaus windows (Ridley et al, 2014).

Whether it is possible to seek a consensus solution depends upon the degree of flexibility each stakeholder offers; clearly, if stakeholders have distinctly different 
desirability profiles and are rigid in their preferences, then the optimization process cannot converge on a solution. However, too much similarity between stakeholders' desirability profiles means that there is not sufficient variation between stakeholders' preference scores and the optimization process will have difficulty selecting the optimal set.

Whether the expected consensus method leads to the selection of the most appropriate compromise solution for multiple stakeholders depends upon the specifics of the data. In the example studied, the maximum expected consensus was achieved by a single decision-maker bearing all the compromise; this may not be agreeable in a real-life situation.

This research used simplified desirability functions to model the preferences of multiple stakeholders. However, the desirability function can take the form of any mathematical function where a criterion value maps to a single probability of acceptance. Small changes in the desirability profile of a single stakeholder can lead to significantly different results, so it is important to focus on accurately defining the desirability function.

Scaling up the problem to include more criteria is feasible. Adding criteria will have only a modest increase in processing time, due to a function call to determine the score for each criterion; obviously, that depends on the complexity of the function. However, increasing the number of decision-makers included in the problem will increase the number of criteria to be optimised, hence that will have a significant impact on processing times.

To conclude, if stakeholder preferences are not incorporated prior to the search, then the process risks rejecting combinations that meet one or more preferences because they are sub-optimal; those discarded options may have other desirable features, such as fulfilling a preference for a specific design. Conversely, focusing on desirability may jeopardise achieving performance targets.

\section{Acknowledgement}

Acknowledgement is given to Eco Design Partnership and to the Findhorn Community for the use of the case study.

\section{References}

Ascione, F., Bianco, N., De Stasio, C., Mauro, G.M. and Vanoli, G. P. (2015). A new methodology for costoptimal analysis by means of the multi-objective optimization of building energy performance. Energy and Buildings, 88, pp. 78-90.

Beume, N., Naujoks, B. and Emmerich, M. (2007). SMSEMOA : Multiobjective selection based on dominated hypervolume. European Journal of Operational Research, 181(2007), pp. 1653-1669.

Clarke, J. (2018). Keynote speech to conference. Building Simulation and Optimization. Cambridge (UK), 11-12 September 2018.

Emmerich, M., Deutz, A., Lia, L., Maulana, and A., Yevseyeva, I. (2016). Maximizing Consensus in
Portfolio Selection in Multicriteria Group Decision Making. Procedia Computer Science. Elsevier Masson SAS, 100, pp. 848-855.

Evins, R. (2013). A review of computational optimisation methods applied to sustainable building design. Renewable and Sustainable Energy Reviews, 22, pp. 230-245.

Goia, F. (2016). Search for the optimal window-to-wall ratio in office buildings in different European climates and the implications on total energy saving potential. Solar Energy. Elsevier Ltd, 132, pp. 467-492.

Harrington, E., C., J. (1965). The Desirability Function. Industrial Quality Control.

Hopfe, C. J. and McLeod, R. (2015). The Passivhaus Designer's Manual: A Technical Guide to Low and Zero Energy Buildings. Routledge. London (UK).

Hopfe, C. J., McLeod, R. S. and Rollason, T. (2017). Opening the black box: Enhancing Community Design and Decision Making Processes with Building Performance Simulation. Proceedings from Building Simulation. San Francisco (USA), 7-9 August 2017.

Jankovic, L. (2012). Designing zero carbon buildings using dynamic simulation methods. Routledge. London (UK).

Kermani, A. and Hairstans, R. (2006). Racking performance of structural insulated panels. Journal of Structural Engineering-Asce. 132(11), pp. 18061812.

Malhotra, N. K. (1982). Information Load and Consumer Decision Making. Journal of Consumer Research, 8(4), pp. 419-430.

Negendahl, K. (2015). Building performance simulation in the early design stage: An introduction to integrated dynamic models. Automation in Construction, 54, pp. 39-53.

Nguyen, A.-T., Reiter, S. and Rigo, P. (2014). A review on simulation-based optimization methods applied to building performance analysis. Applied Energy, 113, pp. 1043-1058

Passivhaus Trust. (2013). Passivhaus - an introduction. http://www.howtopassivhaus.org.uk/sites/default/file s/PH Intro Guide update 2013.pdf

Payne, J. W. (1976). Task Complexity and Contingent Processing in Decision Making: An Information Search and Protocol Analysis. Organisational Behavior and Human Performance, 16, pp. 366-387.

Ridley, I., Bere, J., Clarke, A., Schwartz, Y. and Farr, A. (2014). The side by side in use monitored performance of two passive and low carbon Welsh houses. Energy and Buildings, 82, pp. 13-26.

Scanferla, M. and Motuziene, V. (2017). Energy Efficient Glazed Office Building Envelope Solutions for Different European Climates. Environmental Protection Engineering, 9(4), pp. 470-481. 